\title{
Herança genética da resistência de capim-amargoso ao glyphosate ${ }^{1}$
}

\section{Genetic heritage of the resistance of sourgrass to glyphosate}

\author{
Marcel Sereguin Cabral de Melo²; Danilo Carvalho Pereira da Silva ${ }^{3}$; Lucas Elache Rosa ${ }^{4}$; \\ Marcelo Nicolai ${ }^{5}$; Pedro Jacob Christoffoleti ${ }^{6}$
}

\begin{abstract}
Resumo - A herança genética da resistência ao glyphosate em capim-amargoso (Digitaria insularis) pode ajudar a entender sua disseminação, porém a mesma não foi previamente caracterizada. Estas informações são essenciais para o entendimento da evolução de resistência à herbicidas na agricultura e o fluxo gênico entre plantas resistentes e suscetíveis. Portanto, o objetivo desta pesquisa foi investigar a herdabilidade dos genes de resistência entre os biótipos resistente e suscetível ao glyphosate, através da determinação da suscetibilidade dos biótipos na progênie F1. Para isso foi comparada a suscetibilidade da geração F1 dos biótipos resistente (MG) e suscetível (S), que permaneceram isolados ou induzidos à polinização cruzada através do acondicionamento de panículas em sacos de polinização. O grau de suscetibilidade ao glyphosate foi medido através de curvas de dose-resposta da progênie F1. A geração F1 de plantas oriunda de um possível cruzamento entre os biótipos demonstrou o mesmo padrão de suscetibilidade ao glyphosate que a progênie oriunda da planta mãe. Comparando as médias dos biótipos resistentes com os suscetíveis ao glyphosate foi calculado um fator de resistência de 4,01. Conclui-se que não há a transferência de genes de resistência após indução ao cruzamento entre biótipos, sendo necessários mais estudos para determinar se isso ocorreu devido à espécie ser exclusivamente autógama ou se a resistência é poligênica, não seguindo o modelo de hereditariedade monogênica. Desta forma, a dispersão da resistência do capim-amargoso pode ser atribuída à disseminação de suas sementes, e não à transferência gênica entre biótipos pela polinização cruzada entre plantas, pois o trabalho evidência fecundação cruzada em taxas imperceptíveis pelo estudo.
\end{abstract}

Palavras-chaves: cruzamento; Digitaria insularis; fluxo gênico; progênie

\begin{abstract}
The gene flux through pollen and glyphosate resistance genetic inheritance in sourgrass (Digitaria insularis) is important to understand this species spread, but it was not previously characterized. This information is essential for the understanding of herbicide resistance evolution rate in agriculture and the gene flux between resistant and susceptible biotypes in the field. Therefore, the objective of this research was to quantify resistance gene

\footnotetext{
${ }^{1}$ Recebido para publicação em 17/12/2015 e aceito em 15/03/2016.

2 Doutorando em Fitotecnia na Escola Superior de Agricultura "Luiz de Queiroz", Universidade de São Paulo, Piracicaba-SP.E-mail: <marcel.melo@bayer.com>

${ }^{3}$ Graduando em Engenharia Florestal na Escola Superior de Agricultura “ Luiz de Queiroz”, Universidade de São Paulo, Piracicaba-SP. E-mail: <danilo_carvalho79@hotmail.com>

${ }^{4}$ Mestrando em Fitotecnia na Escola Superior de Agricultura “Luiz de Queiroz”, Universidade de São Paulo, Piracicaba-SP. E-mail: <lucas_rosa88@yahoo.com.br>

5 Gerente Técnico na Agrocon Assessoria Agronômica LTDA., Santa Bárbara D’oeste-SP. E-mail: $<$ mnicolai2009@gmail.com>

${ }^{6}$ Professor Associado do Departamento de Produção Vegetal na Escola Superior de Agricultura "Luiz de Queiroz", Universidade de São Paulo, Piracicaba-SP. E-mail: <pedrochristoffoleti@gmail.com>
} 
inheritance among glyphosate resistant and susceptible biotypes, through the determination of the level of susceptibility to the herbicide in the F1 progeny. it was compared to the F1 generation susceptibility of resistant biotypes (MG) and susceptible (S), which remained isolated or induced to cross-pollination through pollination bags. The sensitivity to glyphosate was measured in the F1 progeny using dose-response curves. The F1 generation plants originating from a possible crossing between biotypes showed the same pattern of glyphosate susceptibility than the parent plant. Comparing the average of glyphosate resistant with susceptible biotypes a resistance factor of 4.01 was calculated. We conclude that there is no transfer of resistance genes after crosspollination induction between susceptible and resistant biotypes. Further research is needed to determine if this occurred due to $D$. insularis species be exclusively autogamous or if the resistance is determined by more alleles, and thus does not follow the model of monogenic inheritance. Therefore, the dispersibility of sourgrass resistance genes can be attributed to seed dispersal and not for gene transfer between biotypes through cross pollination among plants, since this study shows imperceptible cross-pollination rates.

Keywords: crossing; Digitaria insularis; gene flux; progeny

\section{Introdução}

O propósito do manejo de plantas daninhas é minimizar as perdas de produtividade das culturas devido à interferência negativa dessas espécies, evitar condições de colheita desfavoráveis, reduzir o incremento do banco de sementes de plantas daninhas e seleção de biótipos de plantas daninhas resistentes a herbicidas; tudo isso com o menor impacto ao ambiente possível, resultando também em lucratividade ao produtor. A utilização de herbicidas para o controle de plantas daninhas se tornou a prática mais utilizada, uma vez que apresenta menor custo, quando comparado com outros métodos de controle, e de alta eficácia agronômica (Oliveira Jr.; Constantin e Inoue, 2011).

O glyphosate é o herbicida mais utilizado globalmente e vem sendo aplicado há mais de 40 anos em diversos sistemas de produção. A adoção de culturas resistentes a este herbicida e a queda da sua patente no ano de 2000, contribuíram para sua ampla aceitabilidade e adoção (Gianessi, 2004; Duke e Powles, 2008). Esse herbicida tem como mecanismo de ação a inibição da 5enolpiruvilchiquimato-3-fosfato sintase (EPSPs) (EC 2.5.1.19), que é a enzima responsável pela reação de condensação do chiquimato-3-fosfato e fosfoenolpiruvato em
EPSP e fosfato inorgânico, na rota do ácido chiquímico (Geiger e Fuchs, 2002). A inibição da EPSPs resulta no acúmulo de ácido chiquímico e na redução da biossíntese de aminoácidos aromáticos, como fenilalanina, triptofano e tirosina que são fundamentais para a alocação do carbono nas plantas, além de interferir na produção de flavonas, isoflavonas, antocianinas, taninos condensados, ligninas e outros compostos fundamentais para o desenvolvimento vegetal (Amrhein et al., 1980; Taiz e Zeiger, 2013).

As plantas daninhas estão continuamente evoluindo e estão sujeitas à um processo de seleção que pode ser causado por diversos fatores, como o uso de herbicidas. A resistência de plantas daninhas a herbicidas é a seleção de indivíduos adaptados em uma população selvagem, devido à ação de um herbicida. Os biótipos resistentes selecionados se tornaram um dos maiores desafios nos sistemas agrícolas recentemente, sobretudo pelo fato de um número exponencial de novos casos de resistência terem sido reportados nas últimas décadas, nos mais diversos sistemas de produção, associados à alta dependência de herbicidas (Jasieniuk et al., 2008).

De acordo com Gunsolus (2008), biótipo pode ser definido como um conjunto de indivíduos, dentro de uma população, que possuem características fenotípicas 
semelhantes, mas que diferem em poucas características genéticas. Sendo assim, a resistência de plantas daninhas a herbicidas é definida como a capacidade natural e herdável de determinados biótipos, dentro de uma população, de sobreviver e se reproduzir após a exposição a doses de herbicidas que seriam letais a indivíduos normais (suscetíveis) da mesma espécie (Christoffoleti e LópezOvejero, 2008).

Uma das espécies de planta daninha que sofreu grande pressão de seleção pelo uso indiscriminado de glyphosate e está disseminada pelas regiões agrícolas do país é o capim-amargoso (Digitaria insularis). O primeiro caso relatado sobre o surgimento de um biótipo de Digitaria insularis (capimamargoso) resistente ao glyphosate veio do Paraguai, no ano de 2006 (Heap, 2015). Esta espécie possui características como a capacidade de formação de rizomas e touceiras, sendo uma espécie de ciclo perene com metabolismo fotossintético do tipo $\mathrm{C} 4$, além de dispersar suas sementes utilizando correntes de vento por possuir sementes com pilosidade (Kissmann e Groth, 1997; Clayton et al., 2006; Lorenzi, 2008). Estas características, aliadas ao grande percentual germinativo, faz com que esta espécie tenha alta capacidade de disseminação.

Apesar das práticas agronômicas influenciarem a seleção de biótipos resistentes a herbicidas, fatores ligados à genética da planta e a biologia da mesma apresentam papel fundamental no desenvolvimento da resistência. Dentre estes fatores está a frequência inicial de indivíduos resistentes na população, dominância dos genes que proporcionam resistência, tipo de fecundação, adaptação ecológica, número de gerações por ano, taxa de reprodução, longevidade dos propágulos no solo, suscetibilidade da planta ao herbicida, entre outros (Matiello; Ronzelli Júnior e Puríssimo, 1999). Portanto, estudar a hereditariedade e transmissão das características de resistência a herbicidas se torna importante.
O primeiro passo após o surgimento de biótipos suspeitos de resistência de plantas daninhas a herbicidas é realizar testes experimentais comprobatórios da resistência (Owen, 2011; Burgos et al., 2013). Sendo assim, curvas de dose-resposta são realizadas com o intuito de comparar biótipos suspeitos de resistência com biótipos conhecidamente suscetíveis (Beckie et al., 2000).

O fluxo de genes de resistência de uma população resistente a determinado herbicida para outra população suscetível pode se dar pela migração das sementes e também pela dispersão do pólen, caso haja polinização cruzada entre as plantas desta espécie. Portanto, populações em que a taxa de fluxo gênico ocorre através de polinização cruzada terão maiores taxas de dispersão da resistência na população (Jasieniuk et al., 1996). Assim, o fluxo gênico pode aumentar a frequência de alelos e, desta forma indivíduos resistentes na população.

A compreensão dos padrões de herança de características de resistência, bem como o potencial de cruzamento pode ajudar a prever a probabilidade e a velocidade de propagação da resistência a herbicida em uma espécie (Maxwell e Mortimer, 1994). A disseminação da resistência a herbicida controlada por herança poligênica será mais lenta do que quando um único alelo dominante está envolvido (Maxwell e Mortimer, 1994).

O padrão de herança da resistência do capim-amargoso ao glyphosate não é conhecido. Sendo assim, o objetivo é quantificar a taxa de cruzamento de biótipos resistentes e suscetível ao glyphosate e determinar o padrão de herança de genes que conferem resistência.

\section{Material e Métodos}

O experimento foi desenvolvido em casa-de-vegetação do Departamento de Produção Vegetal, com irrigação diária de aproximadamente $4 \mathrm{~mm}$ distribuídos durante o dia, no período de setembro de 2014 a janeiro 
de 2015. O biótipo suscetível (S) foi oriundo de uma área sem histórico de aplicação de glyphosate do município de Iracemápolis - SP, cujas coordenadas geográficas são $\mathrm{S} 22^{0} 39^{\prime} 17.1^{\prime \prime} \mathrm{W} 47^{0} 29^{\prime} 32.39$ ", enquanto que o biótipo resistente (R) foi proveniente do município de Campo Florido em Minas Gerais (MG), cujas coordenadas geográficas são S19 $45^{\prime} 48.80^{\prime \prime} \mathrm{W} 48^{\circ} 34^{\prime} 19.47^{\prime \prime}$ onde o produtor tem um histórico de 3 aplicações de glyphosate anuais nos últimos 5 anos. As plantas deste biótipo sobreviveram a uma dose de glyphosate (RoundUp Transorb R, 480 g e.a. L ${ }^{-1}$, SC, Monsanto) de $1440 \mathrm{~g}$ e.a.ha ${ }^{-1}$, sendo este considerado como supostamente resistente ao herbicida.

As sementes dos biótipos foram semeadas em bandejas preenchidas com substrato comercial adubado, onde germinaram e em seguida foram transplantadas quatro plantas por vaso plástico de $10 \mathrm{~L} \mathrm{e} 2$ vasos para cada biótipo, onde permaneceram até a produção de sementes. Durante a fase de emissão da inflorescência, foram ensacadas em sacos de polinização panículas nas seguintes combinações: uma panícula do biótipo $\mathrm{S}$ junto com uma do biótipo MG (SxMG); uma panícula do biótipo MG junto com uma do biótipo S (MGxS); somente uma panícula do biótipo $\mathrm{S}$ (S) e somente uma panícula do biótipo MG (MG). Após a maturação das sementes as inflorescências foram separadas e designadas de acordo com sua planta de origem vindo primeiramente na nomenclatura adotada, sendo a planta mãe $\mathrm{S}$ ensacada com uma panícula MG com a nomenclatura "SxMG", a planta mãe MG ensacada com uma panícula $S$ com a nomenclatura "MGxS" e as que foram ensacadas sozinhas nomeadas com a sigla do biótipo materno, "S" ou "MG" apenas. Em outros trabalhos o saco de polinização é utilizado após uma polinização artificial ser efetuada, com intuito de evitar a contaminação dos botões polinizados (Souza et al., 2015), o que mostra que as inflorescências ficam completamente isoladas após serem ensacadas.
$\mathrm{Na}$ segunda etapa foram semeadas as sementes das panículas S, MG, SxMG e MGxS em bandejas preenchidas com substrato comercial adubado, onde permaneceram até a emergência, sendo transplantadas duas plantas por vaso plástico de $1,0 \mathrm{~L}$, também preenchidos com substrato comercial adubado e conduzidas até o estádio vegetativo 23 (2 a 3 perfilhos), segundo a escala de BBCH (HESS et al., 1997). Neste estádio, os tratamentos foram aplicados utilizando um pulverizador costal, com pressão constante de 2,0 bar (200 $\mathrm{kPa}$ ) pressurizado com $\mathrm{CO}_{2}$, equipado com ponta do tipo leque Teejet XR 110.02, aplicando um volume de calda correspondente a $200 \mathrm{~L} \cdot \mathrm{ha}^{-1}$. Cada população foi submetida aos tratamentos herbicidas constituídos de sete doses de glyphosate: 120, 240, 480, 960, 1.920, $3.840,7.680$ g e.a. ha ${ }^{-1}$, bem como a testemunha sem aplicação do herbicida glyphosate. $\mathrm{O}$ delineamento experimental adotado foi o inteiramente casualizado, com quatro repetições e oito tratamentos, somando assim 32 unidades experimentais por população aplicada.

Após a aplicação dos tratamentos foram realizadas avaliações visuais percentuais de controle aos 7, 14, 21 e 28 dias após os tratamentos, onde 0 representava ausência total de sintomas, e 100, morte da planta. Após a última avaliação visual de controle foi realizada a coleta da parte aérea das plantas para mensuração de massa seca, após secagem em estufa até peso constante.

Os dados obtidos no experimento foram inicialmente submetidos à aplicação do teste $\mathrm{F}$ sobre a análise de variância. Em seguida, foram ajustados ao modelo de regressão não-linear do tipo logístico no qual as variáveis controle e massa seca foram ajustadas ao modelo proposto por Knezevic et al. (2007), com a equação abaixo.

$$
y=d / 1+\exp [b(\log x-\log e)]
$$

Em que: y é a variável avaliada, $x$ é a dose do herbicida e "b", "d" e "e" são 
parâmetros da curva, de modo que "b" é a declividade da curva, "d" é o limite superior da curva e "e" a dose que proporciona $50 \%$ de resposta da variável.

O modelo logístico apresenta vantagens uma vez que um dos termos integrantes da equação é uma estimativa do valor de C50 ou de GR50 (Christoffoleti, 2002). O C50 (controle de $50 \%$ da população) e o GR50 (redução de $50 \%$ do crescimento) são as doses do herbicida que proporcionam $50 \%$ de controle ou de redução de massa da planta daninha, respectivamente (Christoffoleti, 2002; Christoffoleti e López-Ovejero, 2004). Os resultados para a obtenção das curvas de doseresposta foram fornecidos pelo modelo estatístico usado no programa $\mathrm{R}$.

\section{Resultados e Discussão}

Os parâmetros obtidos através da regressão não-linear para a avaliação de controle visual e redução de crescimento, estão descritos na Tabela 1. É possível evidenciar a diferença entre as populações que foram consideradas suscetíveis (S e SxMG), daquelas que foram consideradas resistentes (MG e MGxS) ao comparar as doses obtidas pelo modelo dentro das colunas DE50 e DE90 mostrados na Tabela 2. Com isso podemos notar que mesmo após a condução das panículas ensacadas entre os biótipos $\mathrm{S}$ e $\mathrm{MG}$, as plantas da geração F1 demonstraram o mesmo padrão de suscetibilidade ao glyphosate que a planta mãe, ou seja, o biótipo SxMG apresentou alta suscetibilidade ao herbicida assim como a planta mãe $\mathrm{S}$ e o biótipo $\mathrm{MGxS}$ demonstrou resistência ao herbicida como a planta mãe MG. Este fato pode ser visualizado claramente nas curvas de dose resposta apresentadas nas Figuras 1 e 2.

Entre os biótipos resistentes (MG e MGxS), a dose necessária para reduzir o crescimento em 90\% (BHS) variou entre $4653,7( \pm 927,75)$ e $5582,6( \pm 1178,99)$ g e.a. $\mathrm{ha}^{-1}$, com dose média de 5118,15 g e.a. ha ${ }^{-1}$ de glyphosate enquanto que para os biótipos suscetíveis S e SxMG a dose necessária para reduzir o crescimento em $90 \%$ variou entre $1235,4( \pm 205)$ e $1314,7( \pm 235,37)$ g e.a. ha $^{-1}$ com dose média de 1275,05 g e.a. ha ${ }^{-1}$ de glyphosate.

Comparando as médias das plantas do biótipo resistente com as plantas do suscetível ao glyphosate foi obtido um fator de resistência de 4,01, caracterizando a diferença de suscetibilidade entre os biótipos. Brunharo (2014) em sua dissertação de mestrado verificou que para reduzir o crescimento em $95 \%$, a população com suspeita de resistência necessitaria quase 13 vezes mais herbicida quando comparada com a população suscetível de Chloris elata. Norsworthy et al. (2008), baseando-se na comparação entre biótipos resistente e suscetível de Amaranthus palmeri, encontrou uma diferença de 79 a 115 vezes maior e uma diferença de 3,4 vezes para dose de glyphosate recomendada para aplicação no campo.

Trainer et al. (2005) encontrou um fator de resistência ao glyphosate de 33 e 39 vezes ao estudar biótipos de buva. Alacón-Reverte et al. (2013), estudaram duas populações da planta daninha Echinochloa colona na Califórnia através de experimentos de doseresposta e encontraram seu fator de resistência de 6,6, com base na DE50. Esse valor encontrado é similar ao encontrado por Travlos e Chachalis (2010), que calcularam o fator de resistência para a espécie Conyza bonariensis variando entre 4 e 7 vezes, porém maior que os encontrados por $\mathrm{Ng}$ et al. (2004) para a espécie Eleusine indica da Malásia.

Mueller et al. (2011), pesquisando através de experimentos de dose-respostas sobre a possível existência de resistência de Eleusine indica ao glyphosate no Tennessee (EUA) com dois biótipos (um com suspeita de resistência e outro conhecidamente suscetível), descobriram um fator de resistência equivalente a 7,4. Plantas escapes de Sorghum halepense provenientes de áreas onde $\mathrm{o}$ herbicida glyphosate vinha sendo usado em lavouras de soja por mais de 6 anos, 
apresentaram fator de resistência da ordem de dose-resposta (Riar et al., 2011). 7,3 vezes após o estudo através de curvas de

Tabela 1. Parâmetros da equação de curva de dose-resposta utilizando os dados de controle visual e redução de crescimento percentual, gerados para as populações $\mathrm{S}, \mathrm{S}$ x MG, MG e MG x S de Digitaria insularis. Piracicaba (SP), 2015.

\begin{tabular}{llccc}
\hline \multicolumn{1}{c}{ População } & $\mathrm{b} \pm \mathrm{SE}$ & $\mathrm{d} \pm \mathrm{SE}$ & $\mathrm{e} \pm \mathrm{SE}$ \\
\hline \multirow{3}{*}{ Controle visual } & $\mathrm{S}$ & $-2,033 \pm 0,244$ & $101,435 \pm 2,290$ & $373,094 \pm 25,139$ \\
& $\mathrm{~S} \times \mathrm{MG}$ & $-1,882 \pm 0,224$ & $101,730 \pm 2,412$ & $412,239 \pm 29,259$ \\
& $\mathrm{MG}$ & $-1,017 \pm 0,121$ & $113,303 \pm 6,206$ & $1227,423 \pm 196,539$ \\
& $\mathrm{MG}$ x S & $-1,060 \pm 0,124$ & $112,312 \pm 5,622$ & $1150,987 \pm 166,328$ \\
\hline & & $\mathrm{b} \pm \mathrm{SE}$ & $\mathrm{d} \pm \mathrm{SE}$ & $\mathrm{e} \pm \mathrm{SE}$ \\
\hline \multirow{5}{*}{ Massa seca } & $1,934 \pm 0,309$ & $99,910 \pm 4,929$ & $422,245 \pm 45,963$ \\
& S & $2,206 \pm 0,395$ & $98,430 \pm 4,832$ & $456,332 \pm 47,284$ \\
& S x MG & $1,337 \pm 0,217$ & $94,345 \pm 5,104$ & $1080,404 \pm 184,734$ \\
& MG x S & $1,457 \pm 0,229$ & $95,577 \pm 4,776$ & $1030,892 \pm 154,782$ \\
\hline
\end{tabular}

"b" é a declividade da curva, "d" é o limite superior da curva e "e" a dose que proporciona 50\% de resposta da variável. *Erro padrão do modelo. Modelo proposto por Knezevic et al. (2007), y=d/1+exp[b $(\log x-\log e)]$

Tabela 2. Doses estimadas (DE) para o controle ou redução de crescimento de $50 \%$ e $90 \%$ (DE50 e DE90) das populações S, S x MG, MG e MG x S de Digitaria insularis, e o desvio padrão. Piracicaba (SP), 2015.

\begin{tabular}{|c|c|c|c|c|c|}
\hline Dados avaliados & População & $\begin{array}{c}\mathrm{DE}^{*} 50 \\
(\mathrm{~g} \text { e.a.ha } \\
\end{array}$ & Erro Padrão & DE* $90\left(\right.$ g e.a.ha $\left.{ }^{-1}\right)$ & Erro Padrão \\
\hline \multirow{4}{*}{ Controle Visual (\%) } & $\mathrm{S}$ & 373,09 & $\pm 25,14$ & 1099,1 & $\pm 167,96$ \\
\hline & $\mathrm{S} \times \mathrm{MG}$ & 412,24 & $\pm 29,259$ & 1324,9 & $\pm 217,86$ \\
\hline & MG & 1227,42 & $\pm 196,54$ & 10628,1 & $\pm 4068,66$ \\
\hline & MG x S & 1150,99 & $\pm 166,328$ & 9142,1 & $\pm 3210,31$ \\
\hline \multirow{4}{*}{ Redução de crescimento (\%) } & $\mathrm{S}$ & 422,25 & $\pm 45,964$ & 1314,7 & $\pm 235,37$ \\
\hline & S x MG & 456,33 & $\pm 47,284$ & 1235,4 & $\pm 205,00$ \\
\hline & MG & 1080,4 & $\pm 184,735$ & 5582,6 & $\pm 1178,99$ \\
\hline & MG x S & 1030,89 & $\pm 154,782$ & 4653,7 & $\pm 927,75$ \\
\hline
\end{tabular}

* Dose estimada da equação do modelo proposto por Knezevic et al. (2007), y= d/1+ exp[b $(\log x-\log e)]$

Carvalho et al. (2011), estudando a planta daninha Digitaria insularis em casa de vegetação, obteve controle visual de $50 \%$ utilizando o herbicida glyphosate nas doses de $63,6,148,8,249$ e 248 g e.a. ha $^{-1}$ para os biótipos S, R1, R2 e R3 (Suscetível, Resistente 1, Resistente 2 e Resistente 3), respectivamente, calculando um fator de resistência de 2,3 (população R1), 3,9 (população R2) e 3,9 (população R3). Os dados para fator de resistência obtidos nesta pesquisa confirmam a resistência ao glyphosate para o biótipo MG, quando comparado aos fatores de resistência encontrados pelos autores citados anteriormente.

Sendo as características de resistência de um biótipo de planta daninha intrínsecas ao DNA, podemos assumir que tais características sejam herdáveis (WSSA, 1998). Sendo assim, uma das hipóteses que podemos inferir baseando-se nos dados obtidos neste trabalho é que a característica de resistência ao glyphosate encontrada nestes biótipos de $D$. insularis pode ser influenciada por mais de uma alteração no genótipo dos biótipos resistentes (resistência poligênica), por não haver nenhuma mudança na resposta ao produto após o cruzamento. 


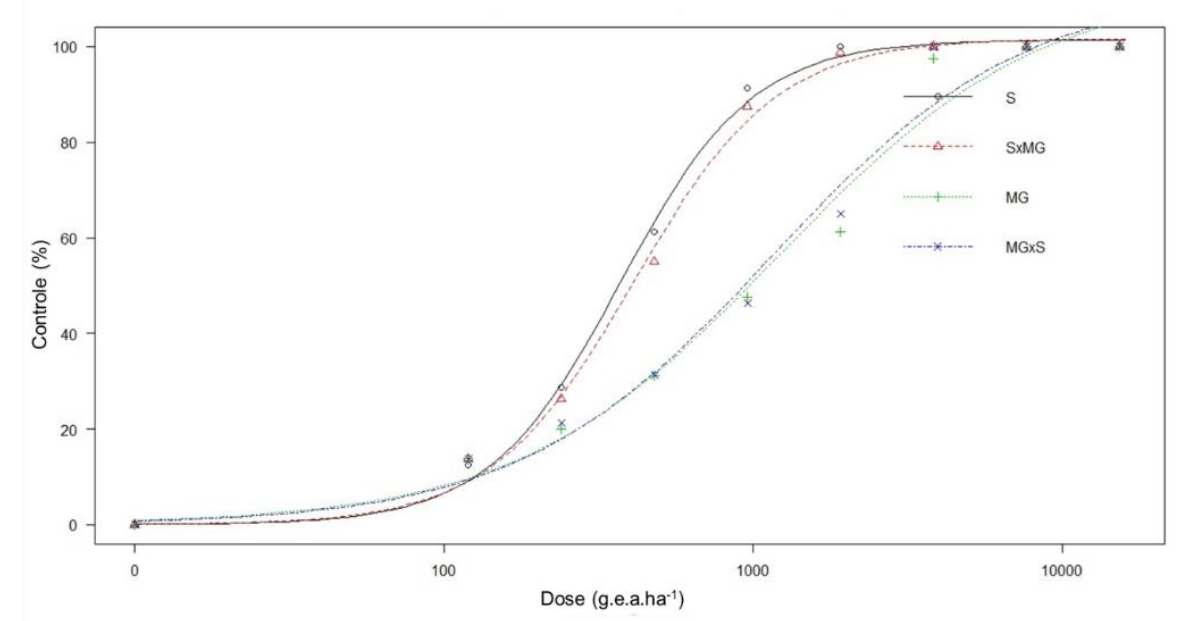

Figura 1. Curva de dose-resposta utilizando os dados de controle visual percentual para as populações S, S x MG, MG e MG x S. Piracicaba (SP), 2015.

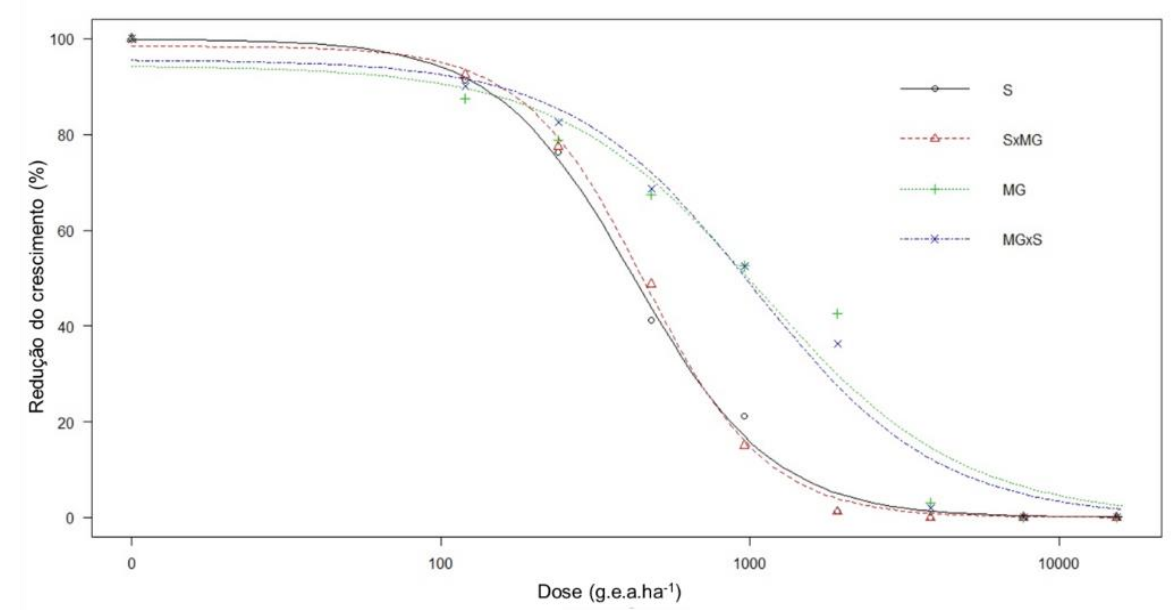

Figura 2. Curva de dose-resposta utilizando os dados de redução do crescimento percentual para as populações S, S x MG, MG e MG x S. Piracicaba (SP), 2015.

Outra possível explicação para os resultados encontrados seria a de que a $D$. insularis é uma espécie autógama. Na literatura não existe nenhuma referência descrevendo a D. insularis como autógama ou halógama. Para Conyza canadensis de natureza autógama utilizando o modelo de hereditariedade simples para a resistência ao glyphosate, associado ao fato de que populações heterozigóticas sobreviveram a aplicações de doses bem acima do recomendado, foi possível prever um rápido aumento na frequência do alelo que confere a resistência quando submetido à seleção contínua pelo glyphosate (Zelaya; Owen e Vangessel, 2004). Brown e Brown (1996) encontraram híbridos de Brassica napus resistente e Brassica campestris suscetível que expressaram resistência ao herbicida glufosinato de amônio.

\section{Conclusões}

Não houve fluxo gênico de resistência entre os biótipos suscetível e resistente, baseando-se nas condições estudadas e 
metodologia adotada neste experimento e utilizando como parâmetro de avalição curva de dose-resposta na progênie F1. Todavia, mais estudos são necessários para determinar se este fato ocorreu devido à espécie $D$. insularis ser autógama ou se a resistência é determinada por maior número de alelos, e que, portanto, não segue o modelo de hereditariedade simples estudado neste trabalho.

\section{Referências}

Alacón-Reverte, R.; García, A.; Urzúa, J.; Fischer, A. Resistance to glyphosate in junglerice (Echinochloa colona) from California. Weed Science, v.61, n.1, p.48-54, 2013.

Amrhein, N.; Deus, B.; Gehrke, P.; Steinrucken, H.C. The site of inhibition of the shikimate pathway by glyphosate II: interference of glyphosate with chorismate formation in vivo and in vitro. Plant Physiology, v.66, p.830-834, 1980.

Beckie, H.J.; Heap, I.M.; Smeda, R.J.; Hall, L.M. Screening for herbicide resistance in weeds. Weed Technology, v.14, p.428-445, 2000 .

Brown, J.; Brown, A.P. Gene transfer between canola (Brassica napus L. and B. campestris L.) and related weed species. Annals of Applied Biology, v.129, p.513-522, 1996.

Brunharo, C.A.C.G. Resistência da planta daninha capim-branco (Chloris Polydactyla) ao herbicida glyphosate. 2014. p.1-153. Dissertação (Mestrado em Fitotecnia) Escola Superior de Agricultura "Luiz de Queiroz", Universidade de São Paulo, Piracicaba, 2014.

Burgos, N.R.; Tranel, P.J.; Streibig, J.A.; Davis, V.M.; Shaner, J.L.; Norsworthy, J.K. et al. Review: confirmation of resistance to herbicides and evolution of resistance levels. Weed Science, v.61, n.1, p.4-20, 2013.
Carvalho, L.B.; Cruz-Hipólito, H.; GonzálezTorralva, F.; Alves, P.L.C.A.; Christoffoleti, P.J.; De Prato, R. Detection of sourgrass (Digitaria insularis) biotypes resistant to glyphosate in Brazil. Weed Science, v.59, n.2, p.171-176, 2011.

Christoffoleti, P.J. Curvas de dose-resposta de biótipos resistente e suscetível de Bidens pilosa L. aos herbicidas inibidores da ALS. Scientia Agrícola, v.59, n.3, p.513-519, 2002.

Christoffoleti, P.J.; López-Ovejero, R.F. Definições e situação da resistência de plantas daninhas aos herbicidas no Brasil e no Mundo. In: CHRISTOFFOLETI, P.J. (Coord.) Aspectos da resistência de plantas daninhas a herbicidas. $2^{\mathrm{a}}$ ed. Campinas: Associação Brasileira de Ação a Resistência de Plantas Daninhas aos Herbicidas (HRAC-BR), 2004. p. 3-22.

Christoffoleti, P.J.; López-Ovejero, R.F. Definições e situação da resistência de plantas daninhas aos herbicidas no Brasil e no mundo. In: Aspectos de resistência de plantas daninhas a herbicidas. 3.ed. Campinas: Associação Brasileira de Ação a Resistência de Plantas aos Herbicidas, 2008. p.9-29.

Clayton, W.D.; Vorontsova, M.S.; Harman, K.T.; Williamson, H. Grass base: the online world grass flora. 2006. Disponível em: <http://www.kew.org/data/grasses-db.html>. Acesso em: 13 mar. 2015.

Duke, S.O.; Powles, S.B. Glyphosate: a once in a century herbicide. Pest Management Science, v.64, n.4, p.319-325, 2008.

Geiger, D.R.; Fuchs, M.A. Inhibitors of aromatic amino acid biosynthesis (glyphosate). In: Böger, P.; Wakabayashi, K.; Hirai, K. (Eds.). Herbicide Classes in Development. Berlin: Springer-Verlag, 2002. p.59-85

Gianessi, L.P. Economic and herbicide use impacts of GR crops. Pest Management Science, v.64, p.124-245, 2004. 
Gunsolus, J.L. Herbicide resistant weeds. Disponível em: <www.extension.umn.edu/agriculture/crops/we ed-management/herbicide-resistant-weeds $>$.

Acesso em: 15 nov. 2015.

Heap, I. The international survey of herbicide resistance weeds. Disponível em: <http://www.weedscience.com>. Acesso em: 20 nov. 2015.

Hess, M.; Barralis, G.; Bleiholder, H.; Buhrs, L.; Eggers, T.H.; Hack, H. et al. Use of the extended $\mathrm{BBCH}$ scale - general for descriptions of the growth stages of mono- and dicotyledonous weed species. Weed Research, v.37, p.433-441, 1997.

Jasieniuk, M.; Ahmad, R.; Sherwood, A.M.; Firestone, J.L.; Perez-Jones, A.; Lanini, W.T.; et al. Glyphosate-resistant Italian ryegrass (Lolium multiflorum) in California: distribution, response to glyphosate, and molecular evidence for an altered target enzyme. Weed Science, v.56, p.496-502, 2008.

Jasieniuk, M.; Brule-Babel, A.L.; Morrison, I.N. The evolution and genetics of herbicide resistance in weeds. Weed Science, v.44, p.176-193, 1996.

Kissmann, K.G.; Groth, D. Plantas infestantes e nocivas. São Paulo: BASF, v.1, 1997. p.510513.

Knezevic, S.Z.; Streibig, J.C.; Ritz, C. Utilizing R software for dose-response studies: the concept and data analysis. Weed Technology, v.21, p.840-848, 2007.

Lorenzi, H. Plantas daninhas do Brasil. Nova Odessa: Plantarum, 2008. p. 495.

Matiello, R.R.; Ronzelli Júnior, P.; Puríssimo, C. Mecanismos de resistência: fatores biológicos, agronômicos e genéticos. In: CURSO DE MANEJO DA RESISTÊNCIA DE PLANTAS DANINHAS AOS HERBICIDAS, 2, 1999, Ponta Grossa. Anais... Ponta Grossa: AEACG, p. 27-40, 1999.
Maxwell, B.D.; Mortimer, A.M. Selection for herbicide resistance. In: Powles, S.B.; Holtum, J.A.M. (Eds.). Herbicide Resistance in Plants: Biology and Biochemistry. Boca Raton, FL: Lewis, 1994. p.1-26.

Mueller, T.C.; Barnett, K.A.; Brosnan, J.T.; Steckel, L.E. Glyphosate-resistant goosegrass (Eleusine indica) confirmed in Tennesee. Weed Science, v.54, n.4, p.562-566, 2011.

Ng, C.H.; Wickenswary, R.; Surif, S.; Ismail, B.S. Inheritance of glyphosate resistance in goosegrass (Eleusine indica). Weed Science, v.52, p.564-570, 2004.

Norsworthy, J.K.; Mcclelland, M.; Griffith, G.M.; Scott, R.C.; Smith, K.L.; Oliver, L.R. Confirmation and control of glyphosateresistant palmer amaranth (Amaranthus palmeri) in Arkansas; Weed Technology, v.22, p.108-113, 2008.

Oliveira JR., R.S.; Constantin, J.; Inoue, M.H. Biologia e Manejo de Plantas Daninhas. Curitiba, PR: Omnipax, 2011. p. 348.

Owen, M.D.K. Weed resistance development and management in herbicide-tolerant crops: experiences from the USA. Journal Für Verbraucheschutz and Lebensmittelsicherheit, v.6, p.85-89, 2011.

Riar, D.S.; Norsworthy, J.K.; Johnson, D.B.; Scott, R.C.; Bagavathiannan, M. Glyphosate resistance in a johnsongrass (Sorghum halepense) biotype from Arkansas. Weed Science, v.59, p.299-304, 2011.

Souza, V.A.; Aguiar, A.V.; Spoladore, J. Metodologia para a polinização controlada em Ilex paraguariensis A.St. Hil. - Aquifoliaceae; Revista Árvore, v.39, n.2, p.315-323, 2015.

Taiz, L.; Zeiger, E. Fisiologia Vegetal. 5. ed. Porto Alegre: Artmed, 2013. p. 719.

Trainer, G.D.; Loux, M.M.; Harrison, S.K.; Regnier, E. Response of horseweed biotypes to foliar applications of cloransulam-methyl and glyphosate. Weed Technology, v.19, .n.2, p.231-236, 2005. 
Travlos, I.S.; Chachalis, D. Glyphosateresistant hairy fleabane (Conyza bonariensis) is reported in Greece. Weed Technology, v.24, p.569-573, 2010.

WEED SCIENCE SOCIETY OF AMERICA. Resistance and tolerance definitions. Weed Technology, v.12, p.789, 1998.

Zelaya, I.A.; Owen, M.D.K.; Vangessel, M.J. Inheritance of evolved glyphosate resistance in Conyza canadensis (L.) Cronq. Theoretical and Applied Genetics, v.110, p.58-70, 2004. 